\title{
CLASSIFICAÇÃO E ANÁLISE DAS UNIDADES DE PAISAGENS NO DISTRITO DE TAPERUABA, SOBRAL, CEARÁ
}

\author{
José Marcos Duarte Rodrigues \\ Doutorando no Programa de Pós-Graduação em Geografia \\ Universidade Federal da Paraíba - UFPB, Brasil. \\ imduarterodrigues@hotmail.com \\ Ernane Cortez Lima \\ Professor-doutor do Curso de Geografia \\ Universidade Estadual Vale do Acaraú - UVA, Ceará, Brasil. \\ ernanecortez@hotmail.com \\ Vanda de Claudino Sales \\ Professora-doutora do Mestrado em Geografia \\ Universidade Estadual Vale do Acaraú - UVA, Ceará, Brasil. \\ vcs@ufc.br \\ Sonia Tatumi \\ Professora-doutora do Departamento de Ciências Marinhas \\ Universidade Federal de São Paulo - UNIFESP, Brasil. \\ sonia.tatumi@unifesp.br
}

\begin{abstract}
RESUMO
O presente artigo classifica e analisa e as unidades de paisagem do distrito de Taperuaba, Sobral, Ceará, através da realização de uma análise ambiental e tipológica. Para tanto, foram determinadas três unidades de paisagem: a planície fluvial do Rio Bom Jesus; as serras secas; os sertões e pés de serra de Taperuaba. Foram analisadas as potencialidades e limitações, identificados os impactos ambientais, diagnostificada a vulnerabilidade e sustentabilidade ambiental, e por último, estabelecidas diretrizes mitigadoras, através de pesquisa bibliográfica, levantamentos de campo e mapeamentos temáticos. A planície fluvial foi considerada como apresentando vulnerabilidade e sustentabilidade moderada. As serras secas e os sertões e pés de serra foram diagnosticadas como área de alta vulnerabilidade e baixa sustentabilidade ambiental. Os principais impactos ambientais de ordem antrópica identificados foram desmatamento queimadas, assoreamento, poluição dos recursos hídricos e diminuição de espécies vegetal e animal. De ordem natural cita-se as inundações periódicas e a erosão do solo. Quanto às diretrizes, propõe-se sobretudo a implantação de APPs, manutenção e/ou recuperação da vegetação, controle das práticas agrícola; práticas de controle de erosão e desenvolvimento do ecoturismo e geoturismo.
\end{abstract}

Palavras-chave: Análise ambiental. Classificação de paisagens. Vulnerabilidade. Sustentabilidade. Nordeste do Brasil.

\section{CLASSIFICATION AND ANALYSIS OF LANDSCAPE UNITS IN THE DISTRICT OF TAPERUABA, SOBRAL, CEARÁ}

\begin{abstract}
This article classifies and analyses the landscape units in the district of Taperuaba, Sobral, Ceara, trough an environmental and typological analysis. Three landscape units were determined: the river plain of Bom Jesus River; dry hills; the hinterland and foothills. Potentials and limitations were analyzed, environmental impacts identified, vulnerability and environmental sustainability diagnosed, and finally, mitigating guidelines were established, trough bibliographic research, field surveys and thematic mapping. The river plain was considere to have moderate vulnerability and sustainability. The dry hills, as well as the hinterlands and mountain ranges were diagnosed as areas of high vulnerability and low environmental sustainability. The main environmental impacts of anthropic nature identified were deforastion, fires, silting, pollution of water resources and reduction of plant and animal species. The main natural impacts were periodic floods and soil erosion. As for the guidelines, it is proposed above all the implementation of APPs, maintenance and/or recovery of vegetation, control of agricultural practices, erosion control practices and development of ecotourism and geotourism.
\end{abstract}

Keywords: Environmental analysis. Landscape classification. Vulnerability. Sustainability. Northeast of Brazil. 


\section{INTRODUÇÃO}

A região Nordeste do Brasil, do ponto de vista dos seus aspectos naturais e do meio ambiente físico, apresenta-se como susceptível a problemas ambientais de elevada importância, resultantes tanto das próprias condições naturais (climas, solos, cobertura vegetal, relevos), quanto de fatores sociais ditos antrópicos - associados com as formas de uso e ocupação do espaço geográfico.

O presente artigo apresenta uma análise dos componentes geoambientais e das unidades de paisagem no semiárido nordestino, tomando como objeto específico de estudo o distrito de Taperuaba, na cidade de Sobral, situado no noroeste do Estado do Ceará (Figura 1), na perspectiva de analisar as variações causadas no meio físico local pelos usos e ocupações sociais. Para subsidiar o trabalho, foi realizada a descrição e análise física do ambiente, associada com classificação de vulnerabilidade e sustentabilidade ambiental das paisagens locais. Foram identificados ainda os principais impactos ambientais resultantes das formas de uso e ocupação, o que permitiu propor diretrizes mitigadoras voltadas para esses problemas.

Figura 1 - Localização do distrito de Taperuaba, Sobral, Ceará.

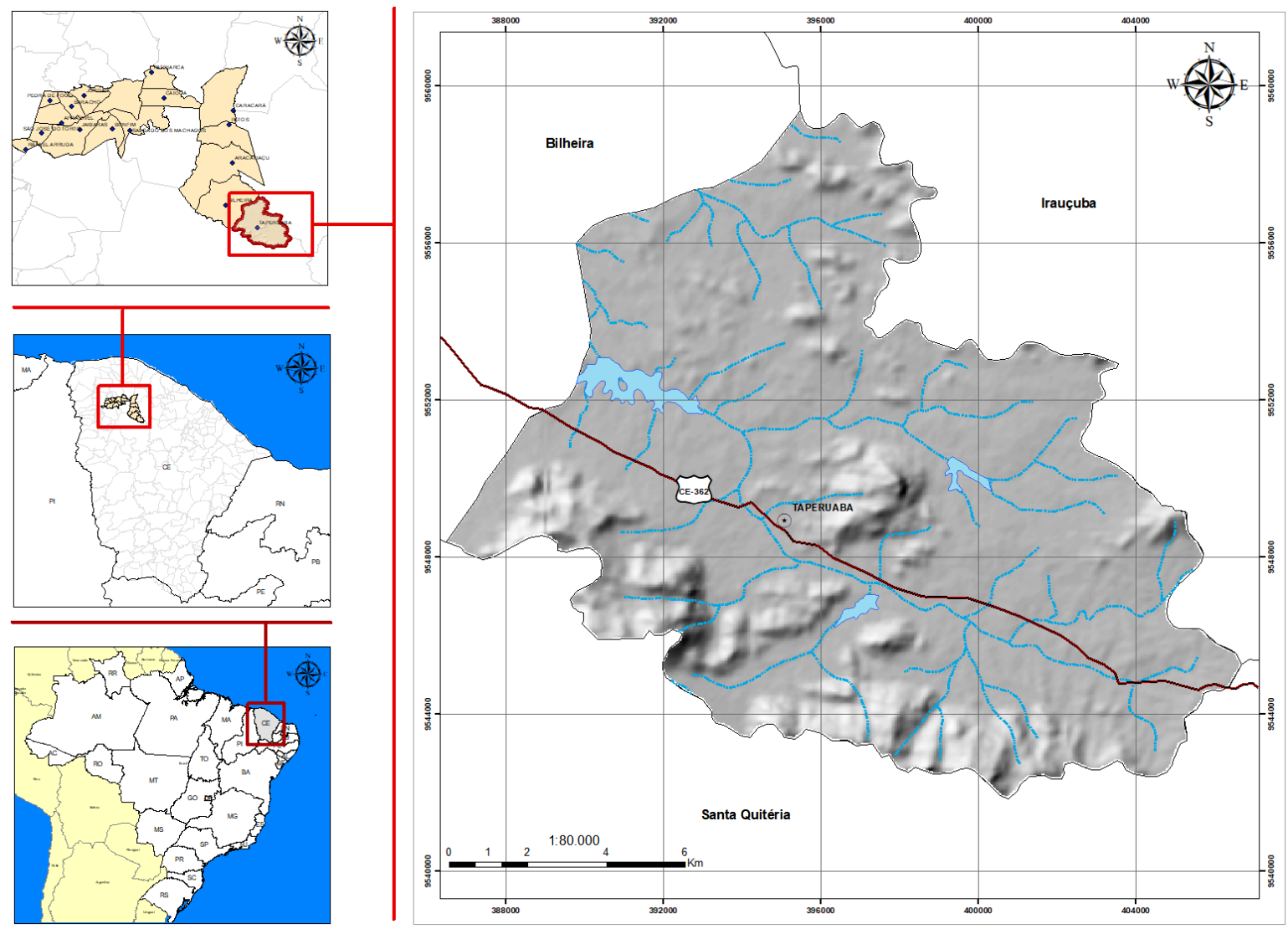

Fonte - os autores.

A área adotada para estudo limita-se a N-NE com o distrito de Juá (Irauçuba), a SE com o distrito de Boa Vista do Caxitoré (Irauçuba), ao S-SW com o distrito de Logradouro (Santa Quitéria) e a NW-N com o distrito de Bilheira (Sobral). Territorialmente o distrito corresponde a $185,3 \mathrm{~km}^{2}$ de área, e possui 6.113 habitantes (IBGE, 2010). A definição do distrito de Taperuaba para a realizacao do estudo aqui apresentado reflete a opção dos autores de utilizar como área de análise a delimitação político-administrativa, por entender que a mesma representa o espaço utilizado para o planejamento e políticas públicas. 
O processo de ocupação e organização do espaço de Taperuaba teve início no fim do século XIX e nos primeiros decênios do século XX (Barros e Holanda, 2017). O processo de povoamento está relacionado com o uso dos recursos naturais, por meio de práticas agrícolas como o cultivo do algodão (Rodrigues, 2016). O cultivo do algodão foi responsável por gerar uma série de impactos na escala ambiental, uma vez que a sua produção aconteceu a partir da expropriação da vegetação nativa. $\mathrm{Na}$ atualidade, o algodão perdeu espaço para a agricultura de subsistência, que também é responsável por descaracterização ambiental, pois é desenvolvida por técnicas tradicionais através do desmatamento e da queimada da vegetação (Barros e Holanda, 2017). Os problemas e as características resultante dessas situações são tratadas nos ítens a seguir.

\section{PROCEDIMENTOS METODOLÓGICOS E TÉCNICOS}

Do ponto de vista da abordagem metodológica, o presente trabalho esta baseado na "análise ambiental". A análise ambiental pautou-se na utilização teórico-metodólogico geossistêmica, mas não implica na identificação de níveis superiores e inferiores da paisagem, tal qual indicado por Bertrand (1972, 1968). Trata -se de uma abordagem na qual se analisa o meio físico natural em uma perspectiva integrada, indicando as relações existentes entre os atributos do meio natural biotico e abiótico, associados com atividades sociais que alteram a dinâmica natural.

Essa abordagem, e tal qual apontada por Claudino-Sales (2004), possibilita a análise do meio ambiente de forma direta e objetiva, com o intuito de caracterizar do ponto de vista natural e antrópico a área objeto de estudo. Pode ser considerada como uma análise sistêmica simplificada, que dependendo do objetivo de estudo, melhor se adequa à caracterização do meio físico natural e antrópico - mas do que a trama hierárquica definida pela abordagem geossistêmica pura, que por vezes engessa as interpretações relacionais.

A análise ambiental permitiu organizar os componentes abióticos, bióticos e antrópicos da área estudada, na perspectiva de se realizar uma distinção de unidades de paisagem. A perspectiva da análise ambiental de inspiração geossistêmica aqui realizada indica que essas unidades de paisagens correspondem às "geofácies" da teoria geossistêmica, as quais implicam na existência de elementos da paisagem comportando determinado tipo de solos, vegetação e exploração antrópica (Bertrand, 1972, 1968).

Para se chegar a tal objetivo, foi realizado levantamento bibliográfico detalhado, trabalhos de campo e mapeamento temático. Os trabalhos de campo ocorreram nos anos de 2017, 2018 e 2019. Em 2017 foi realizado o reconhecimento da área de pesquisa. Em 2018 o foco foi a compreensão empírica dos componentes físico-ambientais que foram mapeados. O retorno ao campo em 2019 foi realizado durante a quadra chuvosa (mês de março), bem como no período seco ( mês de outubro. A partir dos trabalhos de campo, foi realizado o mapeamento temático, o qual foi elaborado por meio de Sistema de Informação Geográfica (SIG) efetivado pelo software ArcGis 10.5, licenciado para a Universidade Federal da Paraíba.

Esse conjunto de atividades permitu a delimitação das unidades de paisagens, para o que definiu-se como fator determinante a geomorfologia, levando-se em consideração que esse componente da paisagem representa feições relativamente fáceis de identificação, sendo, portanto elementos de delimitação mais precisa.

Do ponto de vista das técnicas, coloca-se que o primeiro passo dado na efetivação do trabalho foi revisão bibligráfica dos temas tratados, seguido da elaboração de produtos cartográficos, representando os componentes geoambientais (geologia, geomorfologia, solos, clima, vegetação).

Para a elaboração do mapa temático de Geologia, utilizou-se como referência o mapa de Geodiversidade do Estado Ceará (CPRM, 2014), na escala de 1:500.000. Teve-se como base cartográfica os arquivos vetoriais da Estrutura Geológica e das Unidades litoestratigráficas, disponibilizado pelo Serviço Geológico do Brasil (CPRM, 2014). 
Para o mapa geomorfológico utilizou-se um Modelo Digital de Elevação (MDE), dados de declividade e relevo sombreado, através de imagens TOPODATA/INPE, com resolução espacial de $30 \mathrm{~m}$. Salienta-se que não se trata de mapa morfométrico, e nesse sentido apenas as principais formas de relevo foram representadas.

$\mathrm{Na}$ identificação dos tipos de solos, tomou-se como base os arquivos vetoriais coletados junto à EMBRAPA. Foram realizados também trabalhos de campo para descrição morfológica de perfis de solos, com a finalidade de averiguação dos tipos de solos identificados no arquivo coletado.

O produto cartográfico de uso e cobertura da terra foi produzido pela manipulação de imagem LANDSAT 8, correspondente ao mês de outubro de 2019, através da composição RGB das bandas 4, 5 e 6, por meio da técnica de classificação supervisionada.

Para determinar a vulnerabilidade das unidades de paisagens utilizou-se como como base os potenciais, as principais limitações de uso e o estado de conservação apresentado pelos recursos naturais, de acordo com as premissas de Souza (2000), onde:

- Vulnerabilidade Baixa com alta sustentabilidade: Corresponde a áreas com boa capacidade produtiva, onde suas limitações podem ser mitigadas através de técnicas simples;

- Vulnerabilidade e sustentabilidade moderada: Áreas com capacidade produtiva razoável, plausível potencial hídrico, boa quantidade de acumulação de água, solos moderadamente profundos, boa conservação da cobertura vegetal;

- Vulnerabilidade Alta com baixa sustentabilidade: Área com capacidade produtiva mínima, devido aos aspectos naturais, como alta declividade e/ou com a degradação ambiental praticamente irreversível, ou com sérios problemas de produtividade de seus recursos naturais, com irregularidades climáticas, déficit hídrico, solos rasos, com a presença constante de afloramentos rochosos.

$\mathrm{Na}$ figura 2 apresenta-se um esquema metodológico, onde se tem os componentes naturais na parte abaixo, na parte acima as atividades socioeconômicas e no meio do esquema a etapa de classificação das unidades de paisagem.

Figura 2 - Fluxograma de organização da pesquisa.

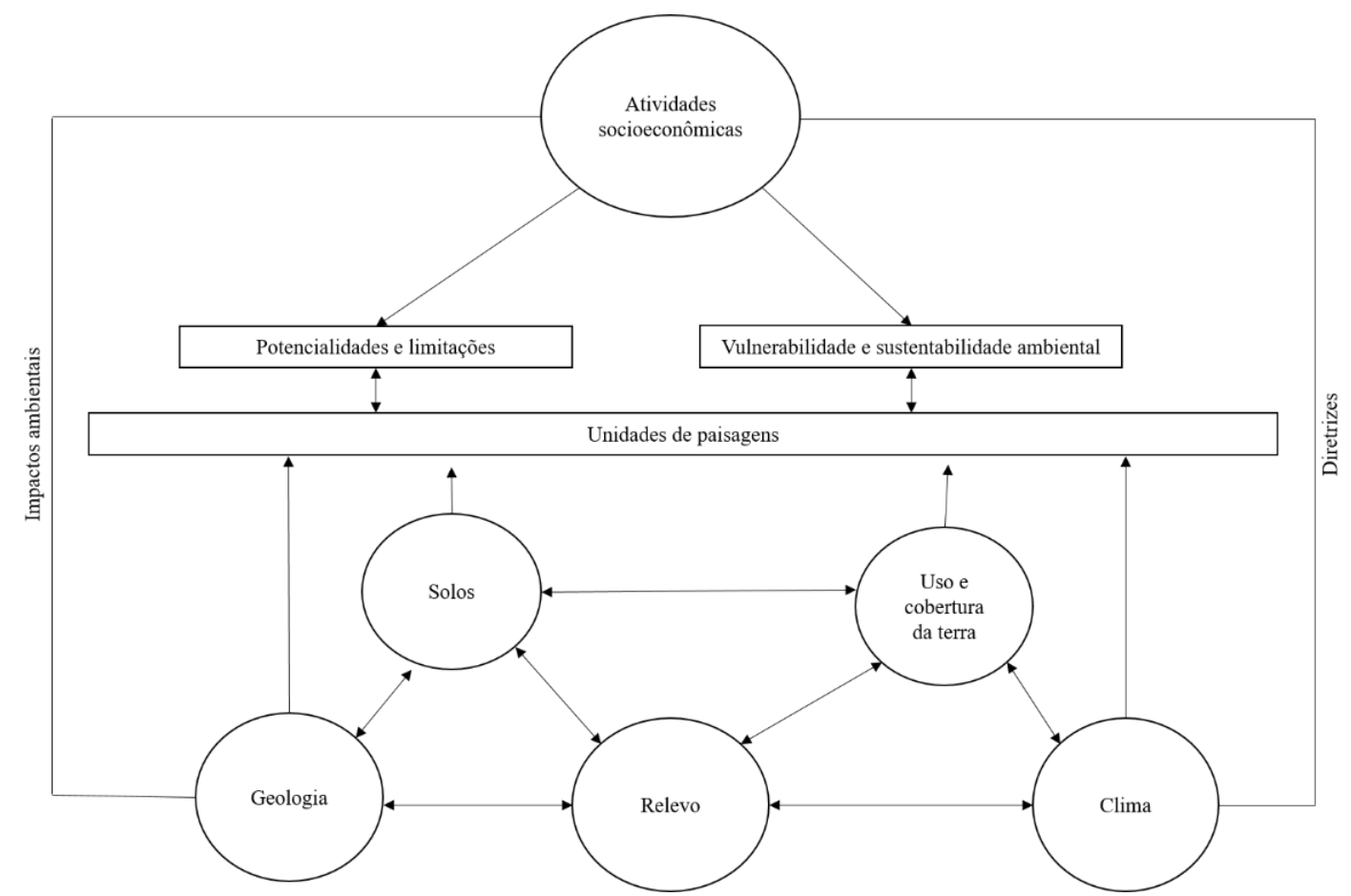


A análise da figura 2 indica o que a classificação das unidades de paisagens está no centro do modelo, em contato direto com os componentes naturais. Tal fato ocorre por se considerar como critério para caracterizar as unidades de paisagem apenas os componentes naturais. Logo acima encontra-se a etapa de classificação das unidades de paisagem, a qual foi realizada de acordo com as potencialidades e limitações, o estado ecodinâmico, a vulnerabilidade e sustentabilidade ambiental. Ao lado esquerdo estão os principais impactos ambientais, tais como entrada de informação, na interface das atividades socioeconômicas com os componentes naturais. Do lado direito estão as diretrizes propostas para o melhor uso dos recursos naturais, as quais representam a saída de informação do modelo adotado.

\section{ANÁLISE AMBIENTAL DO DISTRITO DE TAPERUABA}

Geologicamente, o distrito de Taperuaba localiza-se no Complexo Tamboril-Santa Quitéria, no domínio Ceará Central, na região setentrional da Província Borborema. Litoestratigraficamente, conforme mostra a figura 3 , está representado pelo complexo ígneo anatético Tamboril-Santa Quitéria, também conhecida como Suíte Intrusiva Tamboril-Santa Quitéria (CAVALCANTE; CAVALCANTI, 2014), composta por migmatitos, gnaisses e granitoides com idades criogenianas no intervalo entre 795 e 591 milhões de anos (Neoproterozoico) (CASTRO, 2004).

Figura 3 - Mapa Litoestratigráfico do distrito de Taperuaba.

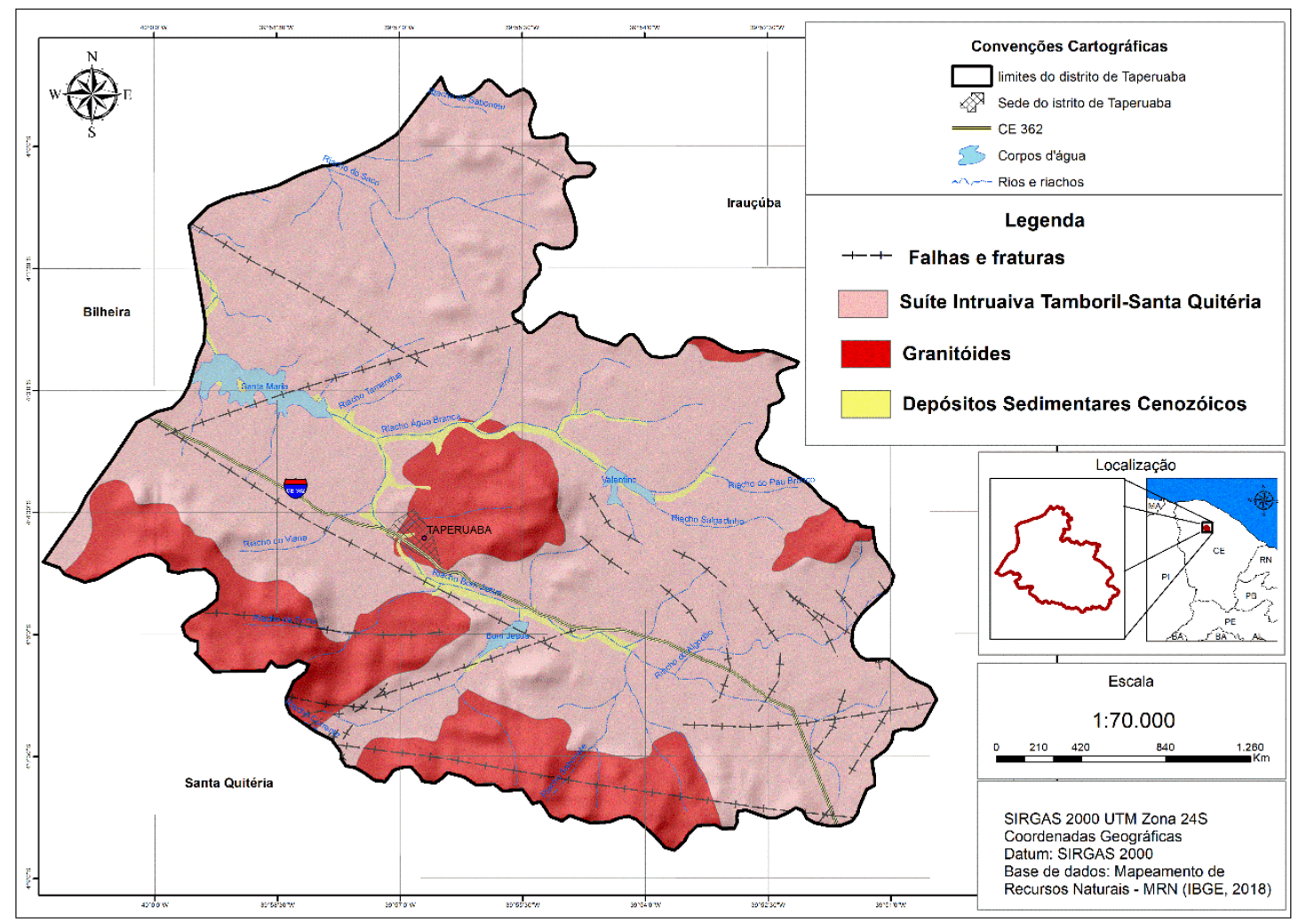

Fonte - Adaptado de CPRM (2014).

Os granitoides são compostos por granito, granodiorito, biotita-hornblenda granito (CPRM, 2014). A suíte intrusiva resulta dos eventos tectogênicos associados com a Orogênese Brasiliana, que representa a principal atividade tectônica a atingir o Nordeste setentrional brasileiro, associada com a colmatagem do continente Gondwana (BRITO-NEVES, 1999). A Orogênese Brasiliana ocorreu ao final do Neoproterozoico, e produziu intenso dobramento, acentuada metamorfização de rochas mais 
antigas e formação de zonas de cisalhamento, nas quais as intrusões graníticas se instalaram (BRITO NEVES,1975).

$\mathrm{Na}$ área ocorre ainda litologia recente, representada pelo Depósitos Sedimentares Cenozoicos, que são formados por argilas, areias quartzosas e quartzofeldspáticas, conglomeráticas ou não, cascalhos e argilas orgânicas/fluvial, de granulação grosseira, presentes na planicie fluvial do Rio Bom Jesus (CPRM, 2014).

Segundo Maia, Bezerra e Claudino-Sales (2010, p. 7), o relevo do Nordeste setentrional, de forma geral, expõe compartimentos elaborados em resquícios morfoestruturais da Orogênese Brasiliana. $O$ conjunto foi reorganizado no Cretáceo, durante a divisão do megacontinente Pangea, no seio do qual o continente Gondwana encontrava-se coligado (CLAUDINO-SALES, 2016; 2002).

De acordo com Claudino-Sales (2016), durante o Cretáceo, devido à reativação das zonas de cisalhamento associadas com a divisão do Pangea, rifts foram abertos no interior do continente, em função do que parcela dos terrenos do Nordeste setentrional foi soerguida. No Cenozoico, as áreas elevadas foram sendo erodidas e rebaixadas a partir da intervenção de processos erosivos comandados por mudanças climáticas. Os setores litológicos e estruturais menos resistentes foram sendo mais intensamente rebaixados, e as rochas mais resistentes, em geral associadas com intrusões brasilianas ou com estruturas paleozoicas, ficaram em ressalto na paisagem (CLAUDINOSALES, 2016; 2002; CLAUDINO-SALES e LIRA, 2011).

Desse amplo processo evolutivo resultaram os seguintes domínios geomorfológicos: superfícies de aplainamento com relevos residuais; maciços cristalinos; platôs sedimentares, fachada atlântica (que recorta ou incorpora os diferentes domínios, ao mesmo tempo em que apresenta características geomorfológicas específicas) e plataforma continental (CLAUDINO-SALES, 2016).

A morfogênese do Quaternário na região Nordeste do Brasil, incluindo a área de pesquisa, vem sendo comandada pela associação das características geológicas/estruturais com fatores climáticos. O clima em Taperuaba é caracterizado por altas temperaturas e baixos índices pluviométricos, com chuvas concentradas em curto espaço de tempo. A figura 4, que retrata dados de 1988-2018 (FUNCEME, 2020), indica que os maiores volumes pluviométricos ocorrem nos meses de janeiro a junho, correspondendo à quadra chuvosa; nos meses de julho a novembro não são registradas precipitações, essas voltando a ocorrer de forma mais significativas no mês de dezembro. Os meses de outubro e novembro são os que exibem as maiores temperaturas, e não há registro de precipitações. Os meses de março e abril, por outro lado, apresentam as menores temperaturas e as maiores médias pluviométricas.

Figura 4 - Médias pluviométricas mensais e temperaturas estimadas para o distrito de Taperuaba/Sobral.

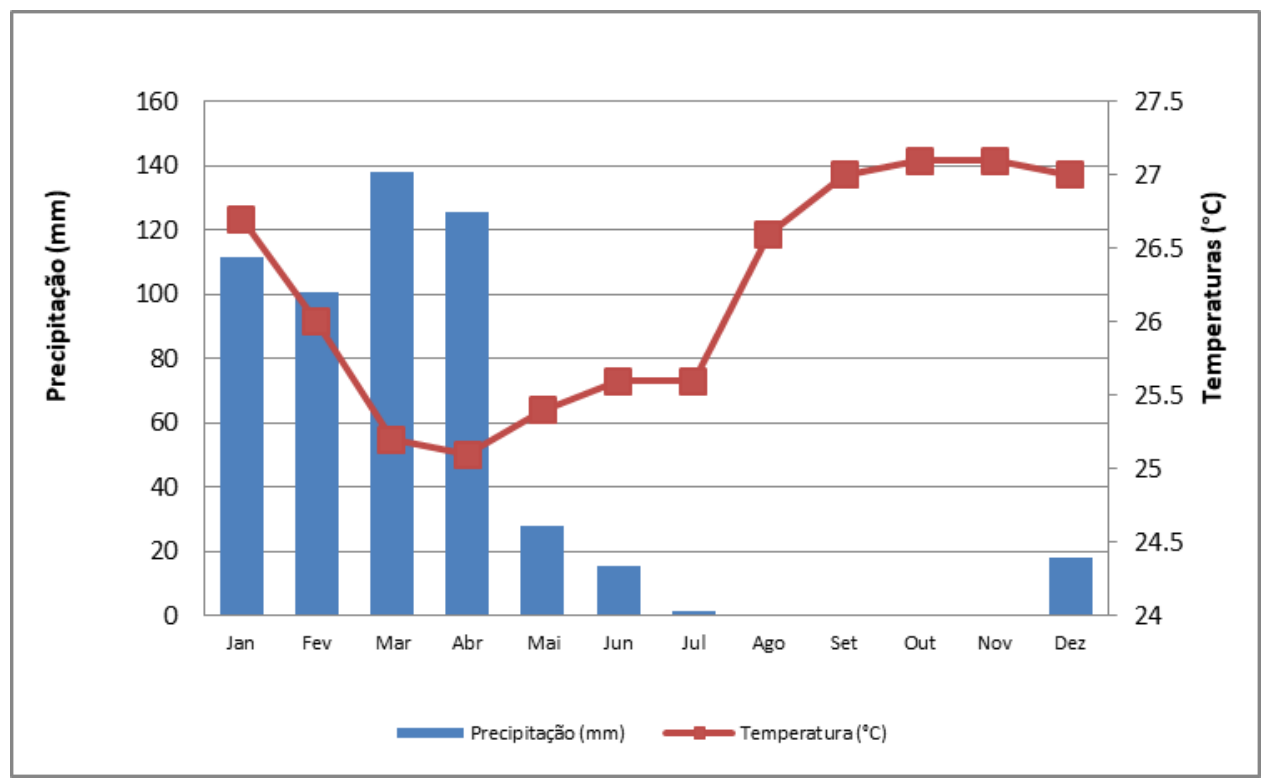

Fonte - FUNCEME, 2020. 
A figura 5 espacializa as unidades de paisagem identificadas na área de estudo, e a figura 6 ilustra essas geoformas. Na plancie fluvial (figura 6A), coloca-se que os sedimentos, visualmente classificados como areias muito grossa e cascalhos, são típicos do clima semiárido que domina na região.

Figura 5 - Mapa geomorfológico do distrito de Taperuaba.

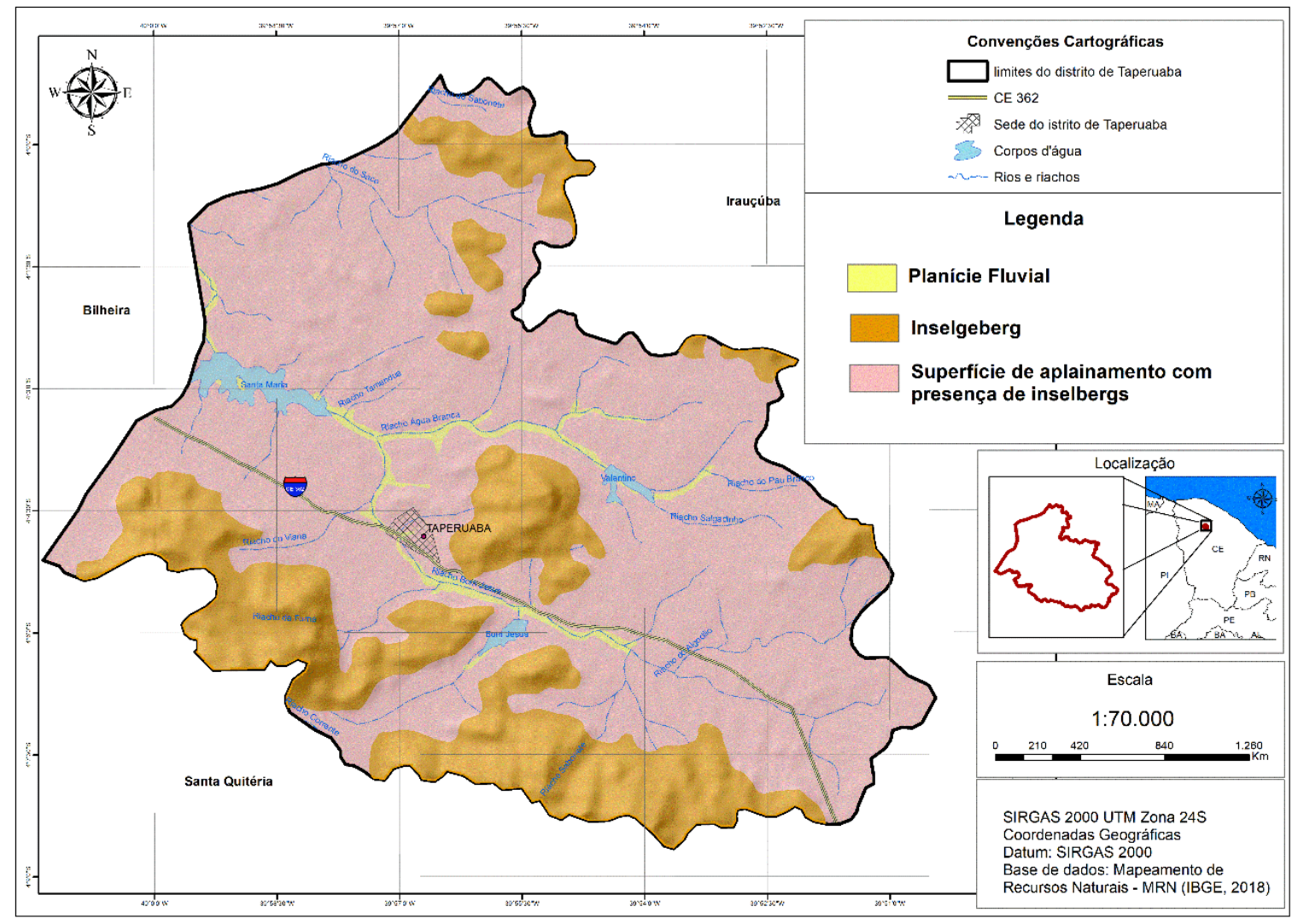

Fonte - os autores.

A superfície de aplainamento comporta relevos residuais e maciços cristalinos de menor extensão, do tipo inselgebirgs (figura 6B) - salienta-se que os inselgebirgs ocorrem com frequência em zonas onde o aplainamento não chegou ao ápice (PEULVAST e CLAUDINO-SALES, 2005). Tais formas de relevo foram esculpidas em rochas cristalinas, correspondentes ao complexo ígneo anatético TamborilSanta Quitéria.

Na superfície de aplainamento foi identificada ainda a ação de processos de morfogênese mecânica associados com morfogênese química do tipo etchplanação, gerando superfícies rebaixadas com afloramentos de granitos localmente denominados de "lajedos" (figura 6B). A identificação de áreas de etchplanação no Nordeste semiárido brasileiro é fato recente (e.g. PEULVAST e BETARD, 2015), e representa um grande avanço na produção do conhecimento geomorfológico da área, tanto regional quanto local.

Quanto aos solos, foram identificados os Neossolos Litólicos, em áreas de relevos declivosos formados a partir da resistência das rochas em relação à atuação do intemperismo, os Neossolos Flúvicos em setores onde o relevo é plano, estando relacionado aos processos de sedimentação aluvial holocênica, e os Luvissolos, que se situam em relevo plano e/ou suavemente ondulado, predominante nas áreas de superfície de aplainamento (figura 7).

Desta forma, foram identificadas áreas com pouca cobertura vegetal, associada com prática da agricultura de subsistência e pecuária extensiva, com solos degradados, áreas com razoável cobertura vegetal e solos pouco erodidos, com a prática predominantemente da pecuária extensiva e, poucas áreas com significativa cobertura vegetal, onde esses tipos de práticas não estão presentes (figuras 8 e 9 ). 
Figura 6 - llustração das geoformas: A. Leito do Rio Bom Jesus no médio curso, em período inicial de estação chuvosa, indicando a existência de areias grossas e cascalhos no aluvião. B. Inselgebirg no distrito de Taperuaba (serra seca). C. Superfície de aplainamento com lajedo, elaborada sobre granitos, como resultado de processos de etchplanação. As fotos foram produzidas no início da estação chuvosa, quando então a vegetação de caatinga dava mostras de início de recomposição, perdendo o cinza típico do período de seca.

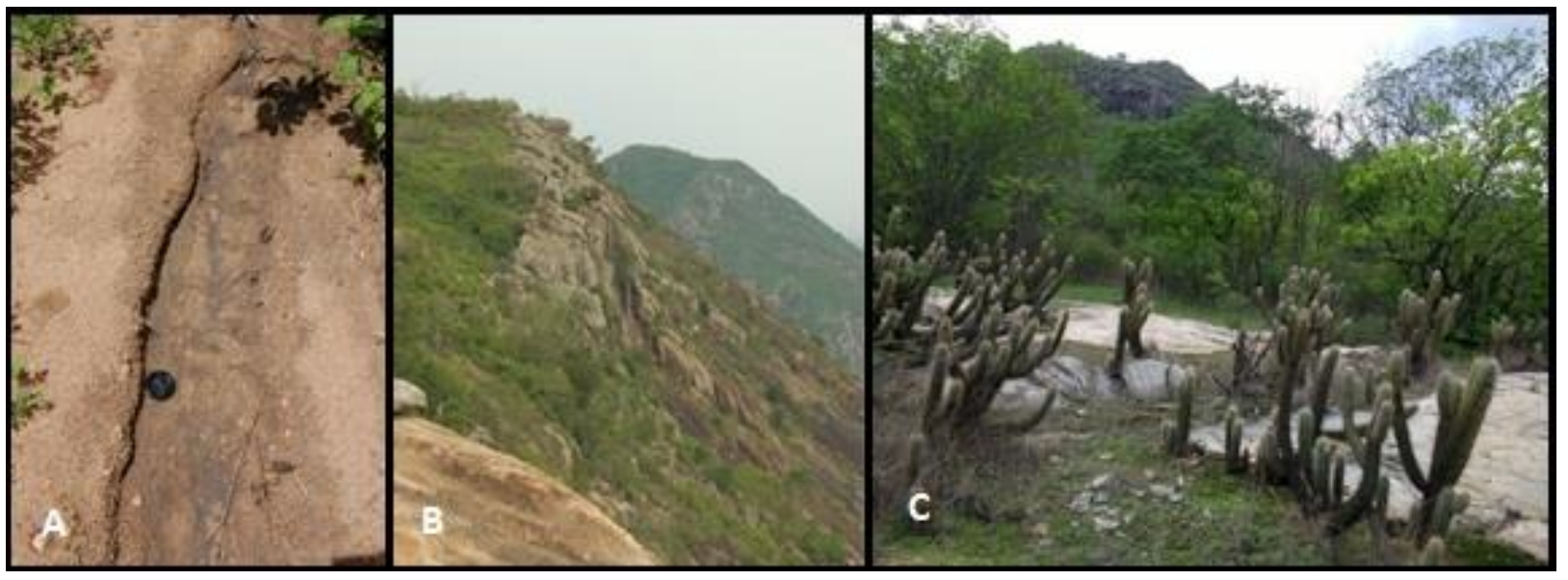

Figura 7 - Tipos de solos do distrito de Taperuaba.

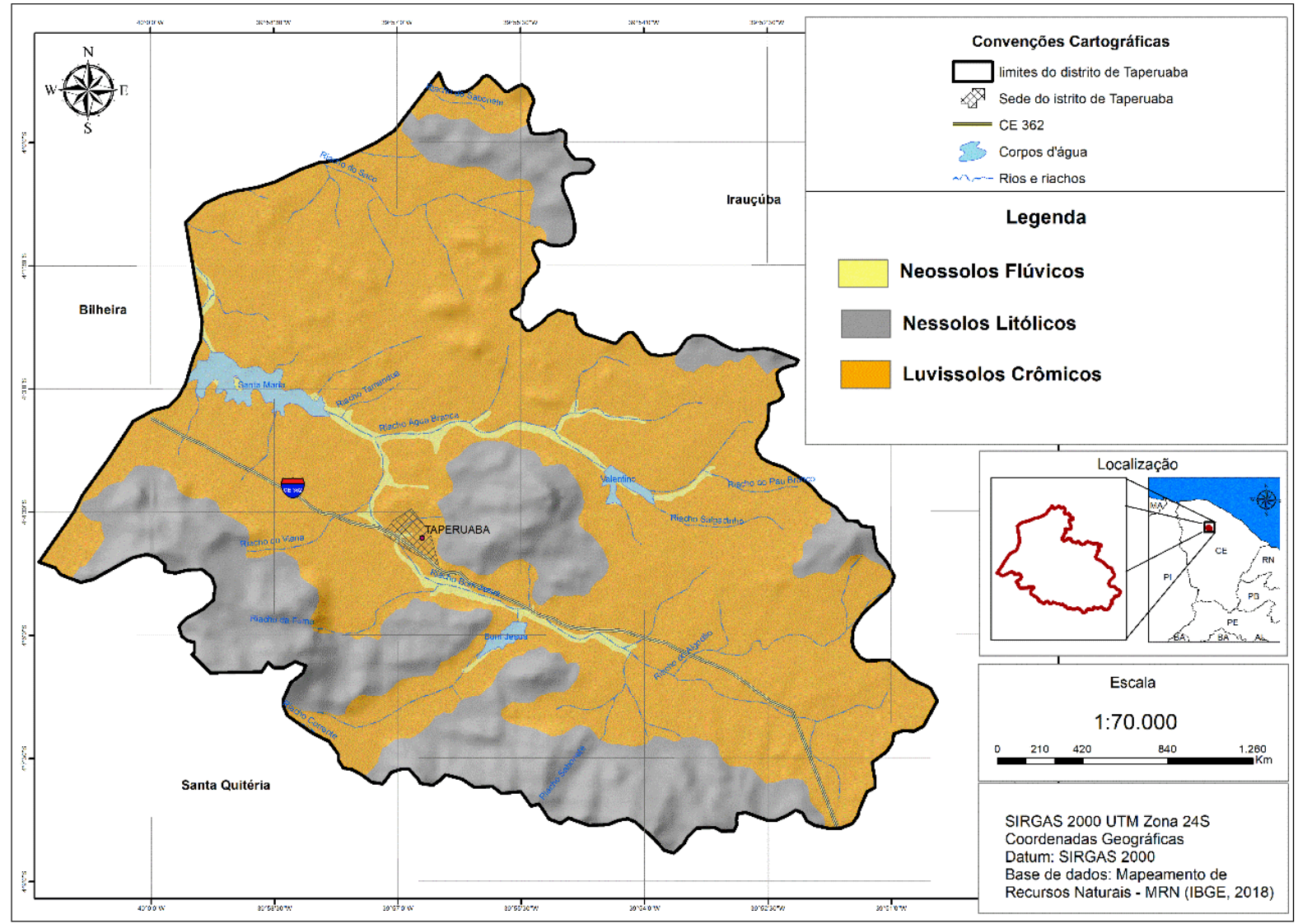

Fonte - Adaptado de SANTOS et al. (2018).

Do ponto de vista das atividades socioeconômicas, reforça-se que o uso e ocupação do espaço local provoca alterações nos atributos naturais, modificando as paisagens. Desta forma, foram identificadas áreas antrópicas agrícolas, com prática da agricultura de subsistência e pecuária extensiva e solos degradados, áreas com caatinga arbustiva e subarbustiva com solos pouco erodidos, com a prática predominante da pecuária extensiva e, com caatinga arbustiva-arbórea de forma pontual Tais fatos indicam forte impacto das atividades socioeconômicas sobre os componentes naturais. 


\section{CLASSIFICAÇÃO E ANÁLISE E DAS UNIDADES DE PAISAGENS}

Para realizar essa análise, foram delimitadas três unidades de paisagem: (1) a Planície Fuvial do Rio Bom Jesus, representando 11, $4 \mathrm{~km}^{2}$, ou seja, $6 \%$ da área total; (2) as Serras Secas, com $55,5 \mathrm{~km}^{2}$, representando $30 \%$ da área; e (3) os Sertões e Pés-de-Serra de Taperuaba, com 118, $4 \mathrm{~km}^{2}$ constituindo $64 \%$ da área (figura 10), identificadas na sequência.

Figura 8 - Uso e cobertura da terra do distrito de Taperuaba.

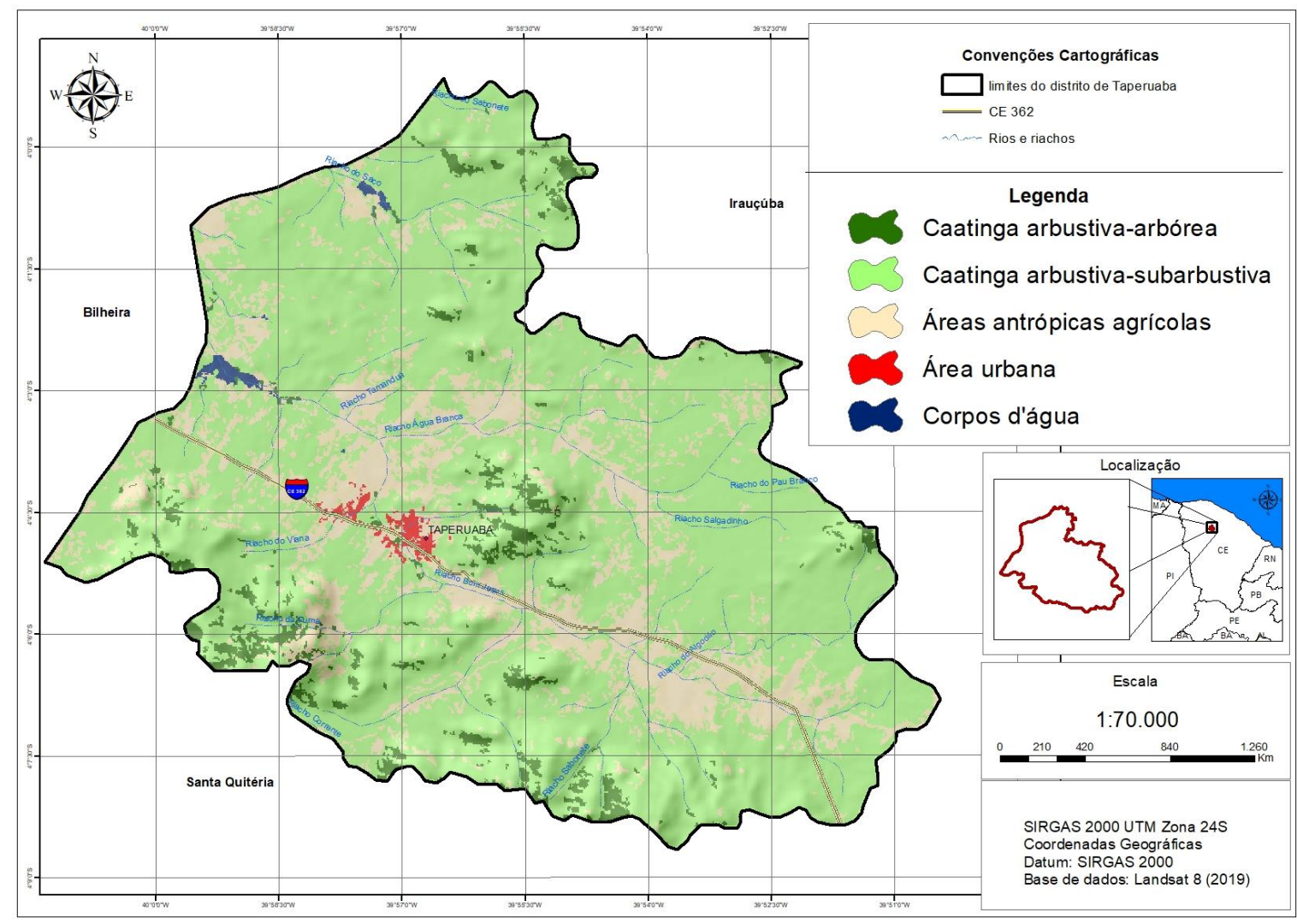

A análise do conjunto das váriaveis acima apresentadas permitiu fazer a análise das unidades de paisagem da área de estudo, conforme pode ser considerado nos ítens a seguir.

\section{Planície Fluvial do Rio Bom Jesus}

Esta unidade de paisagem situa-se no vale do Rio Bom Jesus e seus tributários. Constitui-se geologicamente por depósitos sedimentares do Neopleistoceno, sendo o relevo representado pelas planícies fluviais.

Trata-se de áreas planas sujeitas à inundações periódicas, com distribuição pluviométrica semelhante à de toda a região adjacente, oferecendo razoável disposição hídrica superficial e subsuperficial. Os solos predominantes são os Neossolos Flúvicos (solos aluviais), e a vegetação dominante é a Floresta Mista Dicótilo-Palmácea (mata ciliar e mata de várzea).

Essa unidade de paisagem é utilizada para o extrativismo vegetal e o uso agrícola, sendo que alguns setores apresentam potencial para instalação de olarias. As limitações estão condicionadas à irregularidade das precipitações, às inundações periódicas e à salinização (RODRIGUES, 2016).

Os principais impactos ambientais de ordem antrópica são desmatamento nas áreas de APPs, queimadas, assoreamento, poluição dos recursos hídricos e diminuição do número de espécies e espécimes vegetal e animal. De ordem natural cita-se as inundações periódicas, que em alguns momentos podem prejudicar a lavoura (RODRIGUES, 2016). 
Classificação e análise das unidades de paisagens no distrito de Taperuaba, Sobral, Ceará

José Marcos Duarte Rodrigues

Ernane Cortez Lima Vanda de Claudino Sales Sonia Tatumi

Figura 9 - Classes de uso e cobertura da terra. A. Áreas antrópicas agrícolas. B. Caatinga arbustivasubarbustiva. C. Caatinga arbustiva-arbórea.
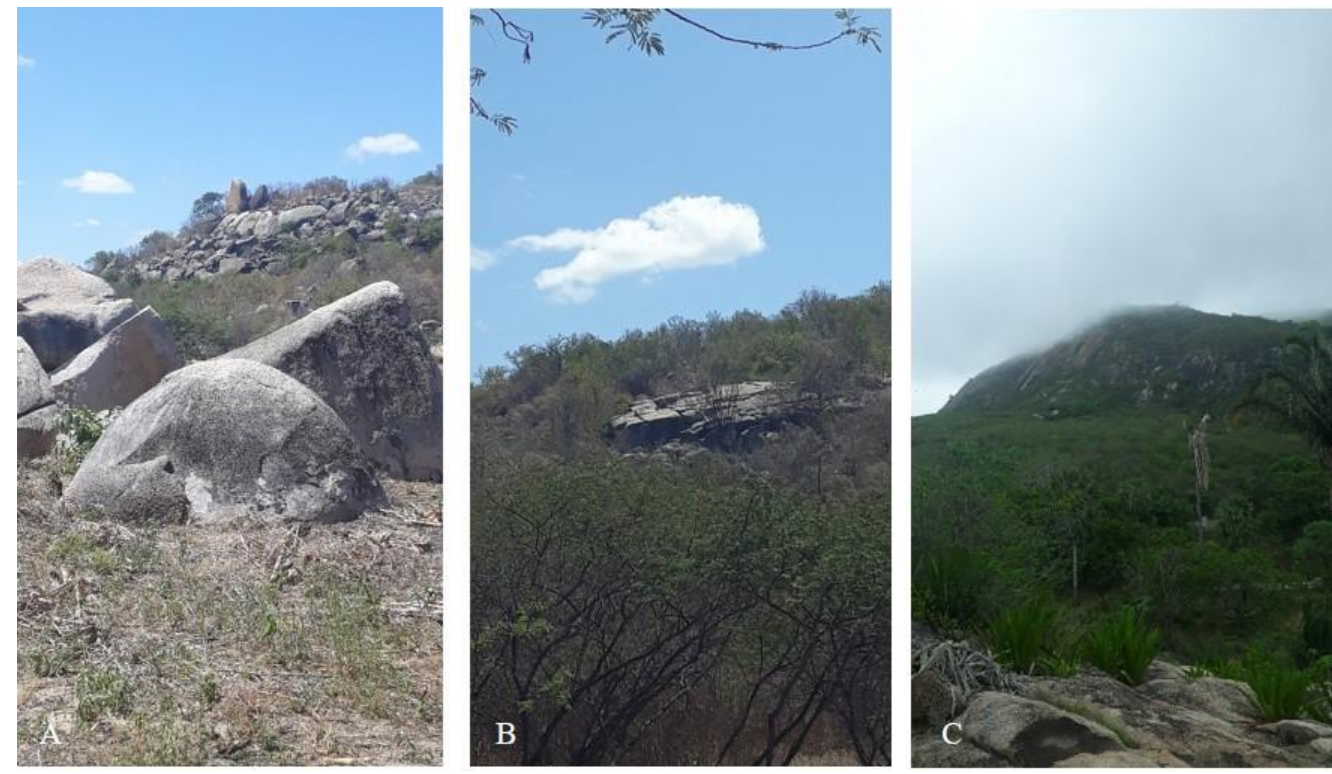

Figura 10 - Mapa das unidades de paisagem do distrito de Taperuaba.

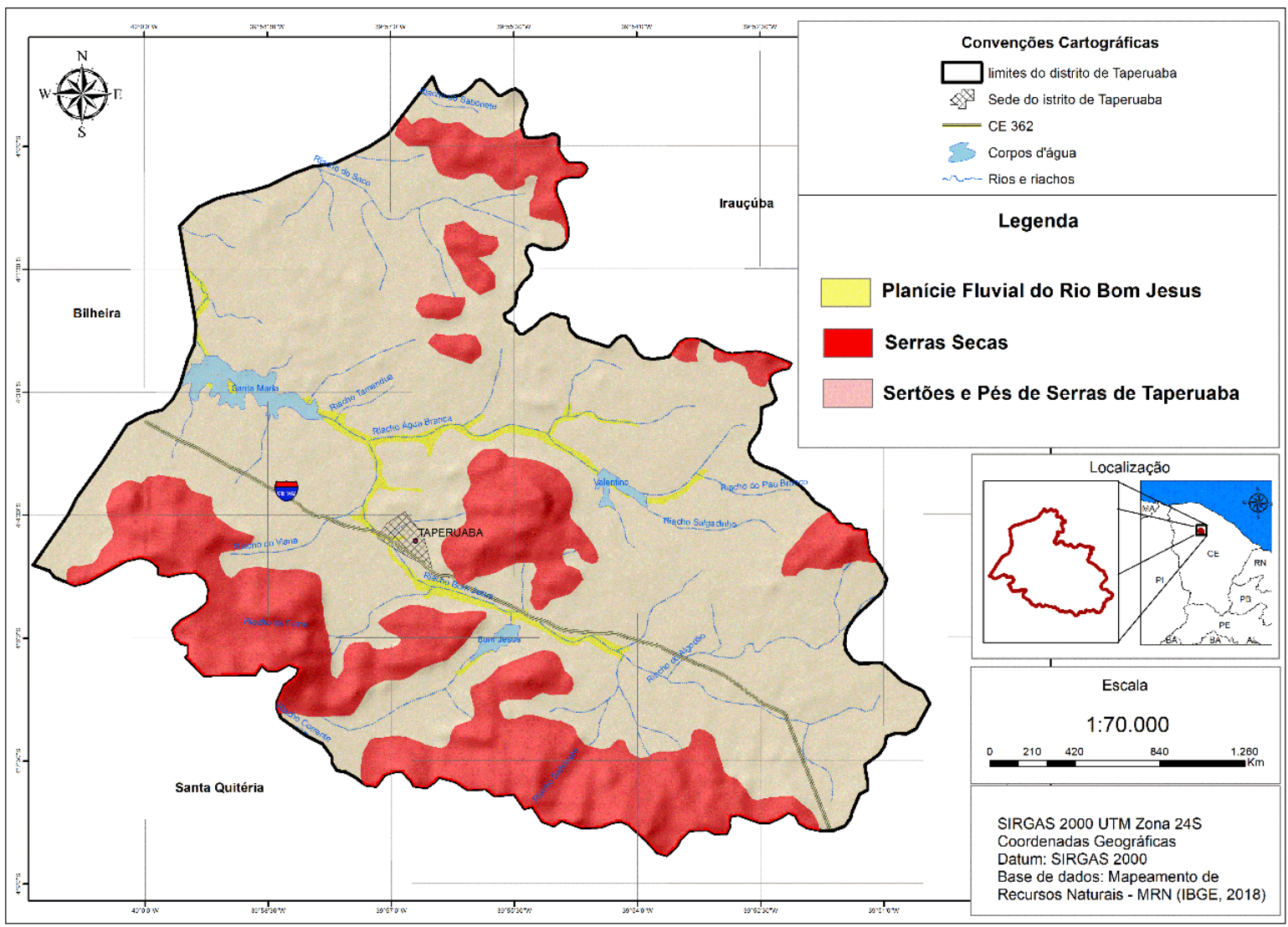

Fonte - os autores.

Nesse ambiente a morfogênese e a pedogênese atuam de forma conjunta (e.g. Melo et al., 2005). São áreas, devido às características do relevo, que apresentam pouca susceptibilidade à erosão. No entanto, a prática da agricultura de subsistência e da pecuária extensiva tem provocado a retirada da 
vegetação, o que provoca instabilidade nesses ambientes. De acordo com essas características, essas áreas foram diagnosticadas como apresentando vulnerabilidade e sustentabilidade moderada.

Tendo em foco todas os atributos apresentados por essa unidade de paisagem, apontam-se as seguintes diretrizes: implantação das áreas de APPs de acordo com a Lei $n^{\circ} 12.651$, de 25 de maio de 2012; desenvolvimento de práticas sustentáveis de extrativismo vegetal; recuperação da mata ciliar; controle da exploração mineral, principalmente da retirada de areia para construção e fabricação de telhas e tijolos.

\section{Serras Secas}

Geologicamente corresponde ao complexo Tamboril-Santa Quitéria, composta por granitos, migmatitos e paraderivados e por granitoides, datados do período Neoproterozoico. O relevo caracteriza-se pelos inselgebirgs e inselbergs, com formas bastante dissecadas e altitude máxima de $700 \mathrm{~m}$, correspondendo aos maiores níveis de declividade com até $75 \%$ Trata-se, portanto, de um ambiente com forte predisposição à erosão.

Embora essa unidade tenha uma significativa representação paisagística com suas elevadas altitudes, estas não chegam a afetar o regime pluviométrico, como ocorre em serras mais elevadas, chamadas de 'serras úmidas' (e.g. LIMA, 2014; BETARD et al., 2007). Assim, o seu regime pluviométrico assemelha-se a de toda a região adjacente. Os solos predominantes são os Neossolos Litólicos associados aos afloramentos rochosos. O tipo de vegetação que prepondera é a caatinga arbustivo-subarbustiva, com espécies do estrato arbóreo.

Esses ambientes são caracterizados por fortes limitações ao uso agrícola. Nestas áreas ocorre o cultivo do milho e do feijão, através do sistema de agricultura tradicional. No entanto, devido à presença de afloramentos rochosos e da declividade, o plantio é dificultado, sendo necessário a utilização de técnicas de manejo específico, o que não ocorre na área em estudo. Tal situação implica em baixa produtividade e em degradação ambiental.

Dentre os impactos ambientais de ordem antrópica destacam-se os desmatamentos em topos de morros, as queimadas, a erosão do solo e a poluição provocada pelo não tratamento dos resíduos sólidos. Coloca-se que existe predomínio da morfogênese sobre a pedogênese, caracterizando o ambiente como instável. Seus potenciais e limitações relacionam-se com suas características naturais, por serem áreas íngremes com afloramentos rochosos. Devido às belezas cênicas, apresentam potencial para o ecoturismo e o geoturismo.

Em adição, estas áreas possuem baixa capacidade produtiva, com alta declividade, solos rasos, apresentando significativo processo de degradação. Portanto, foram consideradas como ambientes de alta vulnerabilidade e baixa sustentabilidade ambiental.

Quanto às diretrizes para esta unidade de paisagem, propõe-se a implantação das áreas de APPs de vertentes íngremes e topos de morros; manutenção e/ou recuperação das matas das encostas ou vertentes íngremes; controle das práticas agrícola; práticas de controle de erosão, principalmente nas vertentes e nos vales; e desenvolvimento do ecoturismo e geoturismo.

\section{Sertões e pés de serras de Taperuaba}

Geologicamente correspondem ao complexo Tamboril-Santa Quitéria do período Neoproterozoico, representado por associação de granito e migmatito. Caracteriza-se por relevo plano a ondulado, correspondente à superfície de aplainamento, com baixas altitudes. Os dados pluviométricos assemelham-se aos da região como um todo. Os solos são do tipo luvissolos, e apresentam uma complexa distribuição fitogeográfica, com espécies pontuais do estrato arbóreo. Há o predomínio da caatinga baixa, de caráter denso e aberto, no estrato arbustivo/subarbustivo e herbáceo, com a presença de cactáceas.

A distribuição vegetal encontra-se espacializada em seu aspecto fisionômico de acordo com o nível de degradação. Nas áreas de maior exploração, devido ao desmatamento e à pecuária extensiva, identifica-se o estrato herbáceo e o arbustivo/subarbustivo, enquanto nos demais setores ocorre estrato arbóreo. De forma geral este ambiente encontra-se fortemente degradado, devido à criação extensiva e o cultivo de subsistência, principalmente pelo cultivo do milho, do feijão e do algodão 
herbáceo. Constata-se, assim, que a área sofre com carência de medidas de recuperação dos segementos territoriais em estado elevado de degradação.

Os principais impactos ambientais de ordem antrópica são o desmatamento e queimadas para a prática da agricultura de subsistência e extrativismo vegetal, o que ocasiona a extinção de espécies e espécimes da caatinga arbórea. Os potenciais e limitações relacionam principalmente com os aspectos climáticos, tais como os longos períodos de seca, fato que limita as atividades agrícolas e a pecuária extensiva, retratando um quadro ambiental problemático.

A morfogênese e a pedogênese atuam de forma diferenciada. Nos setores com fraca cobertura vegetal, a morfogênese supera a pedogênese. Já nos setores onde a vegetação é densa, a pedogênese sobrepõe-se sobre a morfogênese. Desta forma, classifica-se ecodinamicamente essa unidade como ambiente de transição, mas já apresentando instabilidades em alguns trechos mais afetados pela degradação dos recursos naturais.

Verifica-se que estas áreas expõem uma complexa e contraditória correlação entre os componentes fisico-ambientais e antrópicos. Apresenta boa capacidade produtiva, devido as características dos solos, mas conta com vegetação de caatinga bastante degradada, com irregularidades climáticas e com déficit hídrico. Desta forma, foram classificadas como áreas com moderada vulnerabilidade e sustentabilidade ambiental.

Do ponto de vista da conservação, propõe-se para estas áreas: promoção da educação ambiental; adoção de práticas agrícolas sustentáveis; recuperação das áreas degradadas; preservação de áreas com forte cobertura vegetal; apoio aos produtores rurais, no sentido de qualificar a produção.

Os dois quadros a seguir sintetizam os problemas ambientais que foram identificados na área de pesquisa (figura 11) e as propostas de mitigação que foram apresentadas para reverter os problemas detectados (figura 12).

Em síntese, coloca-se que a pesquisa bibliográfica, os levantamentos de campo e o mapeamento temático permitiram fazer um diagnóstico ambiental completo do distrito de Taperuaba, Sobral, de forma a permitir classificar e analisar as unidades de paisagem na perspectiva da vulnerabilidade e da sustentabilidade, apontando-se as principais formas de degradação que atingem a área, bem como indicando-se caminhos para superar os problemas detectados, tal qual exposto nos parágrafos anteriores.

Figura 11 - Quadro indicativo dos problemas ambientais detectados no distrito de Taperuaba.

\begin{tabular}{|c|}
\hline DE ORDEM ANTRÓPICA \\
\hline $\begin{array}{c}\text { Desmatamento nas áreas de APPs, topos de morros e } \\
\text { superfície de aplainamento }\end{array}$ \\
\hline Queimadas \\
\hline Assoreamento da planície fluvial \\
\hline Poluição dos recursos hídricos \\
\hline Erosão do solo \\
\hline Extrativismo vegetal \\
\hline Diminuição de espécies e espécimes da fauna e flora \\
\hline DE ORDEM NATURAL \\
\hline Inundações periódicas \\
\hline Déficit hídrico \\
\hline Erosão do solo \\
\hline
\end{tabular}

Fonte - os autores. 
Figura 12 - Quadro indicativo das diretrizes e medidas de mitigação propostas.

\begin{tabular}{|c|}
\hline Implantação de áreas de APPs \\
\hline Uso de práticas sustentáveis de extrativismo vegetal \\
\hline Adoção de práticas agrícolas sustentáveis \\
\hline Recuperação da mata ciliar e de áreas degradadas \\
\hline Controle da extração mineral \\
\hline Manutenção e/ou recuperação das matas das encostas e \\
vertentes íngremes \\
\hline Práticas de controle de erosão do solo \\
\hline Educação ambiental \\
\hline Apoio ao produtor rural \\
\hline Desenvolvimento do ecoturismo e geoturismo \\
\hline
\end{tabular}

\section{CONSIDERAÇÕES FINAIS}

O presente trabalho apresentou uma classificação tipológica das paisagens naturais presentes no distrito de Taperuaba, município de Sobral, Estado do Ceará. A área analisada representa um segmento do semiárido nordestino típico da região, que se repete com frequência por todo o território regional, podendo ser considerado como exemplo desse tipo de ambiente. Nesse sentido, a análise apresentada é representativa do conjunto semiárido do Nordeste setentrional, e a metodologia pode ser aplicada em outros setores regionais, para se obter um quadro completo dos aspectos naturais, antrópicos e de vulnerabilidade ambiental da região.

O levantamento apresentado nesse artigo tem como meta indicar propostas e soluções para os problemas socioambientais detectados, como forma de potencializar o desenvolvimento econômico sustentável no distrito administrativo em questão. Assim, o próximo passo será apresentar os dados para a administração pública, com o intuito de contribuir nessa perspectiva, de maneira a transformar a pesquisa exposta em exemplo concreto de produção científica aplicada.

\section{AGRADECIMENTOS}

Os autores agradecem à Fundação Cearense de Apoio ao Desenvolvimento Científico e Tecnológico - FUNCAP pelo financiamento da pesquisa.

\section{REFERÊNCIAS}

BARROS, R.O.; HOLANDA, V.C.C. O distrito de Taperuaba-Sobral(ce): um olhar sobre as transformações socioespaciais.III Seminário Regional Comércio, Consumo e Cultura nas Cidades, Anais, Sobral, 2017.

BERTRAND, G. Paisagem e Geografia Física Global. Cadernos de Ciências da Terra-IGUSP, n. 13, 1972

BERTRAND, G. Paysage et géographie physique globale: esquisse méthodologique. Revue géographique des Pyrénées et sud-ouest, v.39, n. $3, \quad$ p.249-272, 1968. https://doi.org/10.3406/rgpso.1968.4553

$\begin{array}{lllll}\text { Caminhos de Geografia } \quad \text { Uberlândia-MG } & \text { v. 21, n. } 77 & \text { Out/2020 } & \text { p. 283-297 } & \text { Página } 295\end{array}$


BÉTARD, F.; PEULVAST, J.; CLAUDINO-SALES, V. Caracterização morfopedólogica de uma serra úmida no semi-árido do Nordeste brasileiro: o caso do Maciço de Baturité-CE. Mercator, Fortaleza, v. 6, n. 12, p.107-126, 2008.

BRANDÃO, R. L.; FREITAS, L. C. B. (Org.). Geodiversidade do estado do Ceará. Fortaleza: CPRM, 2014.

BRASIL. Código Florestal Brasileiro. Lei 12.651, de 25 de maio de 2012. Brasília-DF: Diário Oficial da União, 2012.

BRITO NEVES, B. B. Regionalização geotectônica do Pré-cambriano nordestino. 1975. Tese (Doutorado em Paleontologia e Estratigrafia) - Instituto de Geociências, Universidade de São Paulo, São Paulo, 1975.

BRITO NEVES, B.B. América do Sul: quatro fusões, quatro fissões e o processo acrecionário andino. In: VII SIMPÓSIO NACIONAL DE ESTUDOS TECTÔNICOS, 7., 1999, Bahia. Anais... Bahia: SBG. 1999. p.11-13.

CASTRO, N. A. Evolução geológica proterozóica da região entre Madalena e Taperuaba, Domínio Tectônico Ceará Central (Província Borborema). 2005. Tese (Doutorado em Geoquímica e Geotectônica) - Instituto de Geociências, Universidade de São Paulo, São Paulo, 2005.

CAVALCANTI, J. A. D.; CAVALCANTE, J. C. Evolução geológica. In: BRANDÃO, R. L. (Org.). Geodiversidade do Estado do Ceará. Fortaleza: CPRM, 2014. p. 21-32.

CLAUDINO-SALES, V. Les littoraux du Ceará. Evolution géomorphologique de la zone côtière de l'Etat du Ceará, Brésil - du long terme au court terme. Tese (Doutorado em Geografia Física) Universidade Paris-Sorbonne, Paris, 2002.

CLAUDINO-SALES, V. Geografia, sistemas e análise ambiental: abordagem crítica. GEOUSP Espaço e Tempo, vol 16, p. 125-141, 2004. https://doi.org/10.11606/issn.21790892.geousp.2004.73959

CLAUDINO-SALES, V. Megageomorfologia do Estado do Ceará: História da paisagem geomorfológica. São Paulo: Novas edições Acadêmicas, 2016.

CLAUDINO-SALES, V.; LIRA, M.V. Megageomorfologia do noroeste do Estado do Ceará. Caminhos de Geografia, vol. 12, p. 200-209, 2011.

FUNCEME (Fundação Cearense de Metereologia). PCD Tapearuaba, Sobral, Ceará. http://www.funceme.br/pcd/home?sensor=2\&intervalo=1 h\&periodo=24h\&uf=CE\&instituicao $=1$ \&operad or=AVG\&estacao $=572$. Acessado 1 de setembro de 2020

IBGE-Instituto Brasileiro de Geografia e Estatística. Censo Demográfico 2010. Resultados gerais da amostra. Rio de Janeiro: IBGE, 2012.

LIMA, E.C..A importância das serras cristalinas no semiárido do Nordeste, especialmente no CearáBrasil. Revista da Casa da Geografia de Sobral (RCGS), v. 16, n. 1, p. 89-100, 2014.

MAIA, R. P.; BEZERRA, F. H. R.; CLAUDINO-SALES, V. Geomorfologia do Nordeste: concepções clássicas e atuais acerca das superfícies de aplainamento nordestinas. Revista de Geografia, Recife, v. 5, n. 1, p.6-19, 2010.

MELO, M. S.; CLAUDINO-SALES, V.; PEULVAST, J.P.; SAADI, A.; MELLO, C.L. Processos e produtos morfogenéticos continentais. In: SOUZA, C. R. G.; SUGUIO, K.; OLIVEIRA, A. M. S.; OLIVEIRA, P. E. (Ed.) Quaternário do Brasil. Ribeirão Preto: Holos, 2005. p. 258-275.

PEULVAST, J.P.; CLAUDINO-SALES, V. Surfaces d'aplanissement et géodynamique. Géomorphologie: relief, processus, environnement, vol. 11, p. 249-274, 2005. https://doi.org/10.4000/geomorphologie.605

PEULVAST, J.P.; BÉTARD, F. Landforms and Landscape Evolution of the Equatorial Margin of Northeast Brazil: An Overview. Amsterdam: Springer, 2015. https://doi.org/10.1007/978-3-31918203-2

RODRIGUES, J. M. D. Análise dos sistemas ambientais da sub-bacia hidrográfica do rio Bom Jesus, Taperuaba, Sobral, CE. 2016. Dissertação (Mestrado em Geografia) - Centro de Ciências Humanas, Universidade Estadual Vale do Acaraú, Sobral, 2016. 
SANTOS, H. G. et al. Sistema Brasileiro de Classificação de Solos. 5. ed. Brasília, DF: Embrapa Solos, 2018.

SOUZA, M. J. N. Bases naturais e esboço do zoneamento geoambiental do Estado do Ceará. In: LIMA, L. C; MORAIS, J. O. SOUZA, M. J. N. (Org.). Compartimentação territorial e gestão regional do Ceará. Fortaleza: Editora FUNECE, 2000. p. 5-104.

TSOAR, H.; LEVIN, N.; PORAT, N.; MAIA, L.P.; HERMANN, H.J.; TATUMI, S.; CLAUDINO-SALES, $V$. The effect of climate change on the mobility and stability of coastal sand dunes in Ceará State (NE $\begin{array}{lllllll}\text { Brasil). Quaternary Research, v. } & \text { n. } & \text { n. 217-226, } & \end{array}$ https://doi.org/10.1016/i.yqres.2008.12.001

Recebido em: 05/02/2020

Aceito para publicação em: 16/09/2020 